\title{
FORMAÇÃO CONTINUADA E PESQUISA NA ESCOLA: A PRÁTICA DOCENTE EM FOCO
}

\author{
Rita Buzzi Rausch (FURB/UNIVILLE)* \\ https://orcid.org/0000-0002-9413-4848 \\ Luciane Maria Schlindwein (UFSC) ** \\ https://orcid.org/0000-0003-3463-2746
}

\section{RESUMO}

O trabalho aborda resultados de uma pesquisa-ação realizada em uma escola pública municipal de Blumenau-SC, cujo objetivo foi analisar a relação teoria e prática, registradas em vídeo, de sete professoras dos anos iniciais. As gravações ocorreram nas salas de aula de uma escola pública, uma vez por semana, durante um ano. Paralelamente às gravações, a cada semana as professoras analisaram, coletivamente, uma das aulas. Os aportes teóricos e metodológicos da psicologia histórico-cultural foram fundamentais, tanto para as discussões coletivas, nas quais as professoras problematizavam suas práticas, quanto como ferramenta metodológica na pesquisa. As análises indicaram reflexões densas empreendidas pelas professoras e o impacto nas suas práticas. Pudemos capturar o movimento de transformação e tomada de consciência das professoras. 0 estudo e análise cooperativa interferiram decisivamente nas ações das docentes, ressignificando suas concepções teóricas e suas práticas docentes, provocando repercussão na própria escola.

Palavras-chave: Formação continuada. Prática docente. Reflexão-ação.

\section{ABSTRACT}

\section{CONTINUING EDUCATION AND RESEARCH IN SCHOOL: TEACHING PRACTICE IN FOCUS}

The paper presents results of an action research carried out at elementary public school in Blumenau city, based on the video recording of the teaching practices of seven women teachers working in the early years. The recordings took place in the classrooms of a public school once a week for a year. Parallel to the recordings, each week, the teachers collectively analyzed one of the classes. The theoretical and methodological contributions of historicalcultural psychology were fundamental, both for the collective discussions, in

Doutora em Educação pela Universidade Estadual de Campinas (Unicamp). Professora/pesquisadora do Programa de PósGraduação em Educação da Universidade Regional de Blumenau (FURB) e do PPGE da UNIVILLE.

E-mail: ritabuzzirausch@gmail.com

** Doutora em Psicologia da Educação pela Pontifícia Universidade Católica de São Paulo (PUC/SP). Professora/pesquisadora do Programa de Pós-Graduação em Educação da Universidade Federal de Santa Catarina (UFSC) e do CNPq.

E-mail: luciane.schlindwein@ufsc.br 
which the teachers problematized their practices, and as a methodological tool in the research. The analyzes indicated the dense reflections undertaken by the teachers and the impact on their practices. We were able to capture the teachers' transformation and awareness movement. The study and cooperative analysis decisively interfered in the actions of teachers, resignifying their theoretical conceptions and their teaching practices, causing repercussion in the school itself.

Keywords: Continuing training. Teaching practice. Reflection-action.

\section{RESUMEN}

\section{EDUCACIÓN CONTINUA E INVESTIGACIÓN EN LA ESCUELA: PRÁCTICA DOCENTE ENFOQUE}

El artículo presenta los resultados de una investigación-acción llevada a cabo en la escuela, basada en la grabación de video de las prácticas de enseñanza de siete maestras que trabajan en los primeros años. Las grabaciones tuvieron lugar en las aulas de una escuela pública una vez por semana durante un año. Paralelamente a las grabaciones, cada semana las maestras analizaron colectivamente una de las clases. Las contribuciones teóricas y metodológicas de la psicología histórico-cultural fueron fundamentales, ya sea para las discusiones colectivas, en las cuales las maestras problematizaron sus prácticas, o como una herramienta metodológica en la investigación. Los análisis indicaron las densas reflexiones realizadas por las docentes y el impacto en sus prácticas. Pudimos capturar el movimiento de transformación y tomada de conciencia de las maestras. El estudio y el análisis cooperativo interfirieron decisivamente en las acciones de las docentes, resignificando sus concepciones teóricas y sus prácticas docentes, causando repercusión en la propia escuela.

Palabras clave: Formación continua. Práctica docente. Reflexión-acción.

\section{Introdução}

Este trabalho expressa uma pesquisa cujo objeto é a formação continuada de professores na escola. ${ }^{1}$

Trata-se de uma pesquisa-ação, construída colaborativamente pelas pesquisadoras e por sete profissionais atuantes nos Anos Iniciais do Ensino Fundamental de uma escola pública pertencente à Rede Municipal de Ensino de Blumenau-SC. As sete profissionais envolvidas na pesquisa estavam interessadas em discutir

1 As professoras envolvidas na pesquisa assinaram o termo de esclarecimento prévio, concordando com os termos da pesquisa. Por livre opção, indicaram que seus nomes fossem mantidos na pesquisa. A pesquisa foi realizada com a anuência formal das professoras envolvidas, da escola e da secretaria municipal de educação. e analisar suas práticas docentes e, além disso, dispostas a enfrentar o desafio de se avaliarem mutuamente. Constituiu-se, portanto, uma modalidade de formação continuada centrada na escola, articulada com a pesquisa, propiciando às professoras

[...] lugares de partilha e de reflexão coletiva, particularmente no seio das escolas, que deem corpo as dinâmicas de autoformação participada; trabalhar em conjunto é a melhor maneira de imaginar práticas inovadoras de formação, e estas são essenciais à produção de uma nova profissionalidade docente. (NÓVOA, 1997, p. 38).

O grupo foi constituído com o intuito de buscar um espaço que pudesse superar, ainda 
que em parte, a dicotomia teoria e prática: um espaço de superação praxiológica. De acordo com Sánchez-Vásquez (2011), a teoria e a prática necessitam estar em relação efetiva para que se constitua a práxis. Ainda que seja a atividade prática do homem que gera a transformação sobre a realidade, é a teoria que possibilita que a consciência seja transformada.

Buscamos investigar a relação teoria e prática em um estudo coletivo, tomando como ponto de partida a própria prática das professoras. Buscávamos compreender suas ações docentes e proporcionar um espaço de reflexões na escola. Os aportes teóricos e metodológicos da psicologia históricocultural foram fundamentais, tanto para as discussões coletivas, nas quais as professoras problematizavam suas práticas, quanto como ferramenta metodológica na pesquisa. Empreendemos uma pesquisa-ação, analisando coletivamente os registros videografados, os quais expressavam as ações pedagógicas das professoras em seu movimento.

\section{A Constituição do Grupo}

Na escola campo de pesquisa já existia um processo formativo por meio de grupo de estudos, envolvendo professores dos anos iniciais do Ensino Fundamental. Uma das pesquisadoras já participava deste grupo de estudos, por atuar na escola como coordenadora pedagógica, nesta rede pública de ensino, há treze anos. 0 grupo estudou diferentes abordagens teóricas e metodológicas, sempre em um movimento de buscar compreender sua prática e, também, superar questões que se configuram no contexto escolar, especialmente aquelas relacionadas com aprendizagem, desenvolvimento, ensino etc. Após dois anos de estudos, o próprio grupo assumiu a teoria históricocultural como suporte da prática pedagógica. Os estudos mobilizaram uma reflexão crítica: "Estamos estudando há dois anos e o que mudou na nossa prática pedagógica? Existe relação entre as ideias de Vigotski e nossas ações? Por que não buscamos investigar no grupo essas relações entre teoria e prática?" (Professora Ange).

Questões semelhantes foram provocando o grupo, que estava realmente interessado em compreender e superar suas práticas pelo viés da Psicologia histórico-cultural. Foi assim que esta pesquisa foi se configurando, nos moldes dos princípios da pesquisa-ação. A escolha da pesquisa-ação foi delineada por possibilitar ao grupo, ao mesmo tempo, conhecer e atuar. E, também, por possibilitar a investigação da prática enquanto ela se desenvolve, considerando seu movimento dialético e sua complexidade. Conforme destaca Thiollent (1985, p. 14)

A pesquisa-ação é um tipo de pesquisa social que é concebida e realizada em estreita associação com uma ação ou com a resolução de um problema coletivo e no qual os pesquisadores e os participantes representativos da situação da realidade a ser investigada estão envolvidos de modo cooperativo e participativo.

Nessa perspectiva, a pesquisa-ação busca conscientizar os participantes de suas ações, impulsionando coletivamente alternativas de superação, apresentando como principais características: o caráter participativo; o impulso democrático; a contribuição à mudança. E, neste caso específico, o grupo tinha o objetivo expresso de analisar suas práticas docentes, buscando empreender mudanças. 0 grupo se autodenominou Grupo Reflexão-Ação.

O Grupo Reflexão-Ação era constituído por sete docentes, mulheres, profissionais experientes, todas com mais de oito anos de atuação na educação. Seis delas eram concursadas, efetivas e com jornada de trabalho de 40 horas na escola. Cinco atuavam como professoras dos anos iniciais do Ensino Fundamental e duas faziam parte da gestão escolar, nas funções de coordenadora pedagógica e orientadora educacional. 
Quadro 1 - Características das professoras integrantes do Grupo Reflexão-Ação

\begin{tabular}{|l|l|l|l|l|l|l|l|}
\hline Participantes & Idade & $\begin{array}{l}\text { Tempo de } \\
\text { educação }\end{array}$ & $\begin{array}{l}\text { Tempo na } \\
\text { escola }\end{array}$ & Vínculo & $\begin{array}{l}\text { Função ocupada } \\
\text { escola }\end{array}$ & C. H. & Escolaridade \\
\hline Ange & 28 & 9 & 4 & Efetiva & $\begin{array}{l}\text { Professora } \\
1 \text { o ano }\end{array}$ & $\begin{array}{l}\text { Ens. Médio } \\
\text { Magistério }\end{array}$ \\
\hline Cecí & 50 & 30 & 1 & Efetiva & $\begin{array}{l}\text { Orientadora } \\
\text { Educacional }\end{array}$ & $20 \mathrm{~h}$ & $\begin{array}{l}\text { Mestrado } \\
\text { Educação }\end{array}$ \\
\hline Dori & 38 & 23 & 4 & Efetiva & $\begin{array}{l}\text { Professora } \\
4 \text { o ano }\end{array}$ & $\begin{array}{l}\text { Graduação: Serv. } \\
\text { Social }\end{array}$ \\
\hline Lita & 25 & 8 & 2 & ACT & $\begin{array}{l}\text { Professora } \\
\text { Contraturno }\end{array}$ & $40 \mathrm{~h}$ & $\begin{array}{l}\text { Ens. Médio } \\
\text { Magistério }\end{array}$ \\
\hline Nate & 29 & 11 & 11 & Efetiva & $\begin{array}{l}\text { Professora } \\
2 \text { o ano }\end{array}$ & $\begin{array}{l}\text { Pedagoga } \\
\text { Esp. Alfabetização }\end{array}$ \\
\hline Rosa & 29 & 8 & 13 & 11 & Efetiva & $\begin{array}{l}\text { Coordenadora } \\
\text { Pedagógica }\end{array}$ & $\begin{array}{l}\text { Professora } \\
40 h\end{array}$ \\
\hline Rita & 31 & Efetiva & $\begin{array}{l}\text { Mestranda } \\
\text { Educação }\end{array}$ \\
\hline
\end{tabular}

Fonte: Elaborado pelos autores deste artigo com base em documentos da secretaria da escola pública envolvida na pesquisa.

Consideramos que a constituição do grupo, o sentimento de pertença e a confiança e abertura para as críticas vindouras foi fundamental. Pensar a própria prática é um desafio a ser superado cotidianamente. Buscamos um processo de pensar a própria prática, com o intuito de contribuir para que as professoras assumissem, no dia a dia em sala de aula, uma prática refletida e uma disposição para a análise coletiva de suas práticas.

Esta investigação educativa passou a ter um objetivo maior: a transformação, o aperfeiçoamento da prática, rompendo com um caminhar solitário, que muitas vezes se efetiva nas escolas, socializando-se o que existe de positivo e avançando nos aspectos a serem superados. 0 grupo assumiu o aspecto coletivo que esta palavra suscita, entendido como um campo de interconexões, de entrecruzamentos que buscam processos compartilhados entre seres humanos que perseguem objetivos comuns de aprendizagem. "Reflexão-Ação", no sentido de pensar a própria prática e ressignificá-la, buscando uma constante avaliação crítica e autocrítica, considerando a origem mais profunda e as consequências mais longínquas das nossas ações.

Todas as segundas-feiras à noite, o grupo se reunia na própria escola e assistia, em média, uma hora de prática gravada em vídeo, de uma das professoras participantes. Cabe ressaltar que a filmagem, que foi feita pela coordenadora/pesquisadora, não era planejada com as professoras. Elas sabiam que, naquela semana, parte de sua aula seria filmada para posterior análise coletiva, mas não tinham conhecimento nem do dia, nem do horário das filmagens. E após, realizavam a análise coletiva da aula assistida por em torno de uma hora. A análise buscava identificar aspectos significativos das práticas e também as tensões, conflitos, problemas que iam se configurando durante as aulas.

A cada segunda-feira, durante um ano inteiro, analisava-se a prática docente de uma das professoras participantes, em forma de rodízio. Conseguimos realizar, durante o ano, vinte sessões de análise, e a prática de cada professora pode ser analisada quatro vezes. Todos os 
encontros de análise do grupo também foram filmados, para que, ao final, pudéssemos fazer uma meta-análise, investigando as possíveis mudanças ocorridas no processo.

As discussões teóricas que aconteceram nas análises coletivas reportaram-se, o tempo todo, às práticas das professoras, àquilo que estava sendo discutido e analisado, num processo que visou à unidade dialética entre teoria e prática, apoiando-nos nas ideias centrais de Vigotski acerca dos processos de aprendizagem e desenvolvimento. Esse autor fundamentava a proposta pedagógica da rede a qual a escola pertencia, bem como refletia as concepções de sociedade, ser humano e educação às quais o grupo se alinhava. A leitura, releitura e interpretação dos vídeos possibilitou a construção das seguintes análises: a mediação do vídeo (a imagem do fazer projetada no vídeo como elemento balizador, como instrumento de mediação); a autoanálise (a autoanálise de cada uma das professoras a partir da heteroanálise, das pistas e críticas das colegas ao assistirem aos vídeos); as críticas (críticas feitas pontualmente por uma das professoras frente a indicações, nos vídeos, de que havia transformações efetivas nas práticas, nas posturas, nas orientações pedagógicas feitas em classe); a incorporação da experiência alheia (depoimentos de uma das professoras a partir de análises de experiências de outrem - assistidas e criticadas nas reuniões de análise dos vídeos, sugestões dadas a uma professora e praticadas pela outra); e a construção de uma consciência coletiva.

\section{0 vídeo, as professoras, as práticas, o outro em mim}

Nesta pesquisa, compactua-se com um dos princípios fundamentais de Vigotski (1987), quando ele afirma que o desenvolvimento de qualquer ser humano se efetua a partir das trocas com outros seres humanos. De acordo com esse autor, uma atividade social externa se transforma numa atividade individual interna. Neste sentido, o contexto social é decisivo, uma vez que cada ser humano se constitui enquanto tal pelas indicações, delineamentos dos outros seres humanos que o circundam, significando a realidade na qual estão inseridos. $\mathrm{Na}$ análise empreendida, analisamos os avanços obtidos na ação/reflexão/ação das professoras participantes da pesquisa, focando nas interferências do grupo sobre cada uma das professoras. A mediação do outro passou a ser o eixo de análise.

A mediação é o fator central na obra de Vigotski, constituindo-se no elo epistemológico na formação da consciência humana.

Mas a consciência não só se projeta, se plasma como se sabe a si mesma como consciência projetada, plasmada, ou, o que dá no mesmo, sabe que a atividade que rege as modalidades do processo prático é sua, e que, além disso, é uma atividade procurada ou desejada por ela. A essa consciência que se volta sobre si mesma, e sobre a atividade material em que se plasma, podemos denominá-la consciência da práxis. (SÁNCHEZ-VÁZQUEZ, 2011, p. 295).

O desenvolvimento humano constitui-se em uma atividade conjunta e recíproca. As análises se voltaram para os processos dinâmicos e interativos empreendidos nas trocas de experiências, nas partilhas de saberes, nos diálogos entre as professoras.

0 foco de análise esteve centrado nas transformações instigadas pela mediação entre as professoras e as pesquisadoras, sob a influência do vídeo. Essas transformações puderam ser aprendidas uma vez que as filmagens das aulas das professoras ocorreram paralelamente às analises. Assim, as professoras acatavam as críticas e tentavam replanejar sua atuação docente. Este fato aconteceu com todas as professoras e é perceptível nos encontros de setembro, outubro, novembro e dezembro, quando as aulas analisadas pelo Grupo Reflexão-Ação se referiam às segundas, terceiras, quartas aulas analisadas de tais professoras.

Destacou-se aqui aqueles momentos mais indicativos das transformações e da ação do grupo. Foram selecionados episódios mais significativos do ponto de vista das pesquisadoras, 
empreendendo-se um movimento dialético, num ir e vir, fazendo-se comparações e considerações, procurando indicar a pertinência dos aportes teóricos de Vigotski, especialmente a mediação, a fim de provocar, em cada um dos integrantes do grupo, uma reação reflexiva/ prática.

Isso só é possível, como afirmou a professora participante Rosa, a partir de uma análise da prática do professor. Um estudo para ressignificar a prática somente pode ser feito a partir da própria prática, no momento em que ela ocorre, e não pela análise abstrata, descrita, mesmo que esta descrição seja feita pelas próprias professoras. Assim, pode-se entender que a melhoria da prática acontece de maneira mais efetiva quando se discute a própria prática, ultrapassando debates de seminários, palestras, cursos, o que reforça a relevância deste tipo de pesquisa e a formação continuada na escola.

Ao que parece, o vídeo funcionou como um valioso instrumento mediador, por possibilitar um olhar avaliativo coletivo da prática docente das professoras participantes tal como ela realmente acontece. Rosa, uma das professoras participantes, demonstrou a sua autorreflexão a partir da análise em vídeo de sua prática. Este fato revelou que, dada a rapidez e a quantidade de demandas do cotidiano escolar, as professoras não conseguem parar para refletir sobre o que fazem ou deixam de fazer no dia a dia em sala de aula. 0 resultado disso pode ser a não percepção de seus acertos e erros, a não compreensão do processo de prática docente cotidiana. Ao se confrontarem no vídeo, as professoras se surpreendiam, muitas vezes, tomadas de emoção, com suas ações. Situações cotidianas, já incorporadas no fazer pedagógico das professoras, se constituíam, a partir da análise dos vídeos, em questões a serem discutidas, depuradas, analisadas pelo grupo. Ficou evidente, neste movimento de observação e auto-observação, mediada pelos vídeos, a necessidade de parar, pensar, refletir acerca de suas próprias práticas. A análise e a autoanálise se constituíram em exercícios que propiciaram ressignificações de suas ações pedagógicas.

Ange, outra professora participante, reforçou a importância da filmadora em sala para uma posterior análise e o quanto esta prática a faz crescer, apesar de não ser fácil. "É fácil? Não é fácil ser filmado." (ANGE). Ser filmado para uma posterior análise coletiva implica em mostrar o que há de mais subjetivo no seu fazer diário, revelar seus erros, suas contradições. Contudo, existem também os acertos, as coerências didático-metodológicas, e estas, quando socializadas, podem contribuir para uma possível mudança no fazer docente de outros professores.

Portanto, o próprio vídeo em si já era, algumas vezes, um instrumento suficiente para a professora se autoavaliar. 0 vídeo, como um instrumento de análise coletiva da prática das professoras, foi um revelador fidedigno do fazer das professoras em sala de aula e das mudanças ocorridas durante o processo, pois ele registrou a prática real, concreta de cada docente em todos os aspectos: comunicativa, interativa, gestual, emotiva.

Na primeira vez que o grupo assistiu, em vídeo, à aula da professora Dori, foram destacados muitos aspectos positivos, como, por exemplo, o conteúdo trabalhado, a atividade de dar vida a uma gravura a partir do significado que ela representava a cada aluno, porém a professora recebeu uma crítica séria quando, na frente de toda a turma, chamou a atenção de uma aluna de maneira grosseira.

A atitude grosseira da professora Dori causou estranheza ao grupo. Logo a Dori, sempre tão atenta e carinhosa com os alunos. É, o vídeo realmente registrou o que aconteceu. Dori teve essa atitude sim, que foi reprovada por todo o grupo. 'A gente às vezes pensa assim:' a aula do fulano deve ser assim', depois tu ficas olhando no vídeo e não é nada disso." (DORI).

Esta fala revela a preocupação de Dori com a opinião emitida pelas demais colegas de trabalho após assistirem a sua primeira prática docente em vídeo. Dá a impressão de que a professora se sentiu "nua" e se despiu para 
mostrar o que realmente faz ou deixa de fazer. Não tem mais o que esconder, ela fez o que está comprovado ali. As professoras participantes trabalhavam há algum tempo juntas, todavia, como em todas as escolas, o que elas realmente faziam em sala era quase que desconhecido pelas outras colegas. Vários são os aspectos que dificultam no dia a dia esse conhecimento. Normalmente, quando uma está envolvida com sua turma de alunos, a outra também está; nas reuniões quase não se discutem aspectos da prática pedagógica do professor. Esta pesquisa foi uma forma de as professoras participantes estreitarem relações e ampliarem seu conhecimento acerca do fazer pedagógico de sua colega de profissão, sentindo-se cúmplices umas das outras, ajudando-se mutuamente nos aspectos mais necessários.

Além da utilização do vídeo para uma possível autorreflexão por parte das professoras, esse processo foi enriquecido, e muito, com a análise das outras professoras participantes, pois, muitas vezes, a professora, a partir de uma leitura individualizada, não se dava conta de seus "deslizes", de suas incoerências. As inúmeras possibilidades não refletidas até então por esta professora, e as demais professoras num movimento de construção compartilhada, confrontavam, negavam e rearticulavam ideias, gerando novos conhecimentos.

Após ouvir os depoimentos das colegas do grupo sobre sua aula, neste mesmo dia, quase ao final do encontro, Dori comentou: "Mas eu estou pensando na Priscila [aluna com quem foi grosseira] agora, depois de tudo o que vocês disseram. Eu acho que estou pegando demais no pé dela." Assim, a professora aprende a ver com outros olhos, a observar com atenção o que antes não percebia, a reler sua própria prática. 0 seu processo pedagógico, que era um ato solitário, transformou-se em atos solidários.

No terceiro encontro de reflexão, analisouse pela primeira vez a prática da professora Ange. Nesta aula analisada, a professora estava trabalhando a partir do tema gerador copa do mundo. A professora pediu que cada aluno les- se o texto coletivo acerca do tema elaborado no dia anterior, utilizando para isso o microfone. O texto lido foi construído por todo o grupo, assim, cada aluno tinha o mesmo texto em mãos. Os dois primeiros alunos foram ouvidos por todo o grupo, o que não aconteceu com os demais. Os alunos se dispersaram: brincavam, corriam na sala, conversavam alto, atrapalhando a leitura dos colegas. Ao final, os alunos liam e eram ouvidos simplesmente pela professora.

Após assistir no vídeo a esta aula, o grupo iniciou a análise:

Nate: Uma coisa que eu notei na tua aula é que enquanto um aluno lia, o outro estava atrapalhando, desconcentrando-o. Isso prejudica a leitura do amigo.

Ange: É, mas essa leitura nem estava programada para eles lerem, mas como eles montaram essa leitura, quiseram ler para ver como ficou. Mas é verdade, deu para ver no vídeo, eles não ouvem o colega e eu preciso outra maneira de conseguir com que a turma preste mais atenção.

Nate: Eu penso assim: todos os alunos estavam lendo o mesmo texto, eles já sabiam o que ia acontecer. Então, se de repente cada um lesse uma parte, não seria tão monótono. Eu não gosto disso, que quando um está falando, o outro fala junto.

Ange: Eu coloco muito isso para eles, direto. Se alguém vai lá à frente ler é porque alguém tem que ouvir. E daí, porque vocês não estão ouvindo?

Rita: Isto, Ange, que a Nate colocou sobre a consciência de grupo é algo que eu também percebi. Acho interessante que todos os aspectos sejam levantados entre nós, porque a gente vai intervindo, dando sugestões, afinal formamos um coletivo. Tu promoves atividades tão dinâmicas que ativa os alunos, porém a crítica da Nate faz sentido. Eles precisam ter mais consciência de grupo, nós vivemos em sociedade, e precisamos ter regras, ter limites, e essa consciência precisa começar desde o início da escolarização. Então eu faço assim também: vamos começar, fulano de tal está lendo, se eu vejo que começa a dispersar, paro a atividade até eles tomarem consciência, volto de novo, paro a atividade, para nesse tempinho eles tomarem consciência que eles têm que ficar em silêncio para entender. Entretanto, você enquanto professora precisa estar observando as reações dos alunos, pois se a 
atividade proposta for insignificante, monótona, cansativa, é lógico que você não vai conseguir que os alunos se envolvam.

É possível afirmar que a professora Nate inicia uma crítica à professora Ange afirmando que a dinâmica da aula está mal organizada, resultando em prejuízo para os alunos. A professora Ange se posiciona na defesa, tentando justificar o comportamento dos alunos devido a uma falta de planejamento desta atividade. No entanto, ao visualizar-se no vídeo, acata as críticas da colega com a informação: "Deu para ver no vídeo, né?” Percebe-se aí, mais uma vez, a importância do vídeo como um bom recurso para promover a reflexão acerca do espaço pedagógico.

A pesquisadora, por saber da angústia que esta professora manifestava a respeito do seu domínio de classe, buscou uma maior reflexão a respeito da crítica que Ange recebera, dando sugestões a partir do próprio fazer pedagógico. Mais tarde, a professora, de uma maneira bem humilde e consciente revelou: "Agora que eu me assisti e ouvi vocês falarem, me deu uma ideia. Se no momento da leitura eu tivesse feito um círculo no chão eles produziriam mais... Porque poderíamos mudar as coisas" (ANGE). Vejam que o que Ange fala parece algo muito simples, porém possibilita uma profunda interpretação acerca de que é preciso que o professor perceba suas limitações e queira mudar. É preciso que eles queiram mudar e perceber que isso é possível, que depende principalmente deles, pois como destaca Vigotski (2010, p. 65), é o professor o principal "organizador do espaço social educativo".

Outro aspecto interessante a ser destacado, presente neste episódio, é quando Nate sugere a Ange uma leitura diferenciada, alegando que desta forma as crianças se envolveriam mais nas atividades. É importante ressaltar que antes de Nate sugerir estas leituras diversificadas, Rita já havia sugerido algo parecido na análise da prática da professora Dori no encontro anterior: "É preciso que o professor avance no sentido de ultrapassar a cópia pela cópia, separação de sílabas pela separação de sílabas. Por exemplo: começa-se uma leitura de um texto, 36 alunos leem a mesma coisa. Se cada um lesse uma coisa diferente, daria mais entusiasmo." (RITA).

Este acontecimento indica que as reflexões do grupo têm, provavelmente, proporcionando mudanças nas posturas pedagógicas das professoras. A fala de um componente do grupo vai sendo refletida e internalizada pelo outro e este vai sugerindo ao outro e assim sucessivamente.

Na segunda aula analisada da professora Ange, quando o grupo se reuniu pela sétima vez, não surgiram críticas quanto ao envolvimento dos alunos nas atividades propostas, como também não foram pontuadas mudanças significativas a esse respeito. Entretanto, três meses depois, no $11^{\circ}$ encontro do grupo, feitas, neste intervalo de tempo, análises das práticas de outras professoras, chegou a vez de analisar-se pela terceira vez a prática da professora Ange. Neste encontro foi possível perceber indicativos de que as críticas e sugestões feitas na primeira análise da prática desta professora resultaram em possíveis transformações, não só conceituais, mas também de ordem prática, sendo visivelmente percebidas no vídeo assistido neste dia.

Faz-se importante descrever a aula, para melhor compreensão do leitor: nesta aula, a professora organizou os alunos sentados no chão, em círculo, e cada aluno tinha uma caixa cheia de brita. Em pares, as crianças iam contando e somando a brita contida em suas caixas. A professora circulava por entre as duplas de alunos, interferindo e auxiliando quando solicitada. Cada uma das duplas foi ao quadro e escreveu o resultado obtido na soma das duas caixas. Um dos alunos escrevia e o outro observava e dava sugestões acerca da escrita. Cada dupla chegou a um resultado diferente, pois em suas caixas havia quantidades diferentes de brita. Após esta primeira atividade, a professora solicitou que os alunos separassem a brita em grupos de dez e descobrissem quantos grupos poderiam formar. Uma dupla ajudava a outra sempre 
que era preciso. A professora fazia os alunos pensarem na relação entre o número que a dupla havia escrito no quadro e a quantidade de dezenas que eles formaram, para ver se estava correto. Construíram também operações numa folha, a partir da brita que eles possuíam, de duas e três parcelas. Ao final, dividindo a brita em dois grupos, os alunos elaboraram histórias matemáticas envolvendo operações de adição e subtração. A dinâmica de aula utilizada pela professora partiu de material concreto para a construção de conceitos matemáticos. Todos os alunos participaram ativamente, respeitando as outras duplas, olhando, ouvindo, prestando atenção e comparando se o seu resultado era maior ou menor que o dos colegas. A professora parava, direcionava a atenção dos alunos nas atividades de uma maneira muito criativa e inteligente. As análises do Grupo Reflexão-Ação desta aula giraram em torno do seguinte:

Rosa: 0 que eu observei na tua aula, Ange, foi o respeito que os alunos tinham com o colega que estava apresentando, observando, contando. $\mathrm{Eu}$ acho que isso favorece a compreensão e a colaboração.

Ange: Eu acho que esta colaboração se deu até porque um tinha uma quantidade diferente do outro. Porque nenhum sabia qual era a quantidade de um e de outro.

Rosa: Aonde despertava a curiosidade deles.

Rita: Mas percebe-se um trabalho de conscientização também. Hoje eu percebi que tu paravas, chamava a atenção, pedia para eles respeitarem um ao outro. Devagarzinho, eles estão começando a respeitar, eles já estão mudando a partir da tua mudança. Eles estão bem mais seguros, pedindo informações, esperando, um exigindo que o outro participe. Eu acho que foi uma boa conquista.

Ange: Depois, no final da aula, vieram duas alunas e disseram: 'Professora, até que hoje nós nos comportamos bem, né?'

Rita: Eles também percebem.

Nate: Às vezes, Ange, a turma é ativa. Só que a gente coloca na cabeça que os alunos nunca vão parar, perturbam, só que a gente tá deixando que internalizarem essas verdades, que são assim mesmo. Eles são ativos, isso é muito bom, mas isto não justifica não fecharem um pouco a boca e prestar atenção em alguns momentos.

É possível perceber que a tônica da crítica à aula da professora Ange, neste encontro, é completamente outra. A professora Rosa, logo no início da análise, afirma que o respeito entre os alunos foi algo que lhe chamou muito a atenção e afirmou a importância deste aspecto para uma maior compreensão e colaboração entre os alunos. A professora Ange justificou que esta colaboração aconteceu devido à diferença das quantidades de brita que os alunos possuíam. Verificou-se que a professora justificou o envolvimento dos alunos nas atividades de uma forma muito parecida com a sugestão feita pela professora Nate, três meses antes. Este fato possivelmente ficou marcado na mente da professora, a tal ponto de ela praticá-lo e nomeá-lo como fator principal do envolvimento dos alunos na atividade. A sugestão dada pela pesquisadora, também da primeira prática analisada, foi percebida no fazer da professora deste dia, sendo destacada por Rita como uma evidente transformação da sua maneira de conduzir as atividades.

Pela comparação das duas análises da prática da professora Ange, percebe-se evidências de uma possível mudança no fazer pedagógico da professora. 0 que na primeira prática filmada foi destacado como aspecto negativo, surge na terceira prática analisad como aspecto positivo no parecer do grupo. Houve uma mudança significativa no agir da professora para sua aula passar de uma análise negativa para uma análise positiva do grupo, no mesmo aspecto. Além da crítica que foi feita, certamente as análises que aconteceram no meio deste processo, em que a professora analisada pode assistir às práticas das outras professoras acerca de como envolvem os alunos nas atividades, foram um fator que também contribuiu com esta mudança. Assim, ações da professora criticadas em uma determinada análise são ressignificadas por esta mesma professora, a ponto de se destacarem como aspectos relevantes da sua aula. 
Foi possível perceber no decorrer das análises, que as sugestões dadas a uma professora foram praticadas também por outra. No encontro do dia 21 de setembro, em que se analisou a aula da professora Ange, a professora Rita reforçou a importância de se oportunizar trocas de conhecimento com pessoas mais experientes nas aulas. Nesta aula, a professora fez um passeio ao redor da escola, tentando identificar os diferentes tipos de vegetação existentes, já que o tema estudado no momento eram as plantas.

Rita: Eu não sei se vocês perceberam na filmagem, quando a Ange estava ali perto do pé de limão com as crianças. De repente, um servente que estava ali por perto foi ao encontro do grupo e ficou ali, olhando, observando. Aí a Ange disse 'oi' para ele e ele disse 'oi' para ela. Ele ficou ali um tempo e depois saiu. Aí a Ange continuou explicando. E eu ali filmando e pensando o quanto a Ange poderia ter aproveitado este momento. E, olha, foi só pensar e ouvi a Ange chamando: 'Ei, seu Walmor, esse pé aqui pode ser utilizado para fazer chá?' Tu vês, esse processo é que anima, porque além de valorizar, ele tem todo um conhecimento, uma experiência. Ele mais do que ninguém conhece quantas árvores tem na escola, que tipos de árvores existem. Esse é o trabalho dele, é preciso que o professor aproveite este conhecimento do seu Walmor.

Ange: É, realmente. Na hora eu vi um pé de alcachofra. E quando vi o pé de alcachofra, um aluno disse que não era chá. 0 outro disse que era boldo. Aí fiquei com dúvida e chamei o seu Walmor.

Ceci: Acho que com isso também a gente estabelece outra relação. Porque na hora que você chamou o seu Walmor e perguntou 'Para que serve isso?', você mostrou para a criança que conhecimento de valor não é só aquele que você tem. Você está demonstrando que existem conhecimentos diferentes, que os outros têm conhecimento e que é na interação que a gente consegue avançar.

0 que se evidencia nessas falas é que a contribuição do servente aconteceu somente porque a professora estava com dúvidas. Não foi algo planejado, com o intuito de se promover trocas mais significativas entre os alunos e o servente da escola. Entretanto, mesmo sem uma intenção consciente da professora, esta troca aconteceu e foi muito valorizada pelo grupo. Ceci deixa claro que o resultado desta interação que ocorreu entre os alunos e o servente pode ter contribuído no entendimento de que todos os seres humanos têm conhecimento e que esse conhecimento é diferenciado de pessoa para pessoa. 0 auxiliar de serviços gerais da escola demonstrou saber mais sobre os tipos de plantas existentes na escola do que a professora. Tal fato mobilizou a professora e a turma na valorização dos conhecimentos específicos e cotidianos.

Após as reflexões feitas nesse dia sobre a importância de se oportunizar, em sala, trocas com pessoas mais experientes, constata-se, um mês e meio depois, na análise da aula da professora Dori, o espaço dado às mediações com pessoas mais experientes. Dori havia solicitado que seus alunos fizessem entrevistas, sobre o tema corpo humano, com várias pessoas da comunidade e convidou, junto com seus alunos, o presidente da Associação de Moradores para que nesse dia participasse de um debate pré -planejado com seus alunos acerca da questão da falta de espaço para lazer no bairro.

Dori: Meus alunos fizeram uma entrevista sobre o coração com o Doutor Serafim, ele é cardiologista lá no Hospital Santa Catarina.

Rita: Eu achei isso muito legal e gostei também da participação do Presidente da Associação, em sala, na explicação das prioridades do bairro.

Infere-se que as reflexões feitas na análise da aula da professora Ange, em que se discutiu a importância das trocas em sala de aula, tenham incentivado a professora Dori a planejar suas aulas de maneira mais interativa e dinâmica e concretizá-las com seus alunos. Assim, todas as considerações positivas e ou negativas que surgiram nas análises do Grupo Reflexão-Ação que foram feitas às diferentes professoras, serviram para que cada uma fizesse uma espécie de autoavaliação de seu fazer docente, modificando ou reafirmando ações, mesmo que esta análise não tenha sido feita exclusivamente para elas. 
Participar dessa pesquisa, já no início desse trabalho coletivo/reflexivo, contribuiu para que as professoras participantes se tornassem mais reflexivas, pesquisadoras atuantes de sua própria prática. É o que revela a professora Nate, no segundo encontro de análise do grupo:

Agora que eu estou participando desta pesquisa, eu penso cada vez que vou dar uma atividade para eles, o para quê eu estou dando isso. Se tu pensas, percebe que muitas vezes está dando uma atividade só por dar. Hoje faltavam 20 minutos e eu pensei que atividade vou dar. Gente, pra quê? Tinha vinte minutos e tinha que inventar uma atividade em minha cabeça. Claro que mesmo pensando a gente continua fazendo abobrinhas. Às vezes eu chego na sala da Ange e eu critico o que ela está fazendo, ela me critica, mas a gente faz tanta coisa boba ainda.

A professora revela que agora ela "pensa" antes de realizar qualquer atividade. 0 conhecimento que surge neste pensar, ou seja, a partir da reflexão de sua prática cotidiana, é o mais aproveitável e útil para entender a prática e transformá-la.

Na medida em que o professor incorpora em seu fazer didático um processo de reflexão e análise crítica do próprio trabalho, ele pode, ao identificar os problemas e dificuldades, equacionar alternativas que o ajudem a superá-las, o que certamente reverterá na melhoria do ensino e consequentemente (espera-se!) da aprendizagem dos alunos. (ANDRÉ, 1998, p. 80).

A professora passou a investigar a própria prática a partir da auto-observação e, consciente de suas limitações, está alerta para o seu próprio trabalho, o que lhe permite utilizar-se como objeto de investigação.

Outro aspecto que essa fala revela, é que a relação existente entre as professoras participantes do Grupo Reflexão-Ação ultrapassou os encontros pré-estabelecidos para a análise e continua nos seus fazeres do dia a dia. Isto revela uma estreita intimidade/cumplicidade profissional entre as professoras. Elas se tornaram pessoas que valorizam a opinião das outras, vão às salas das colegas, questionam, trocam ideias. É possível interpretar a partir disso, também, que apesar de participarem sete profissionais da escola, as críticas e sugestões surgidas no Grupo Reflexão-Ação poderão se espalhar para muitos outros componentes da escola e sair dela. Esta reflexão mútua constante sobre a prática é fundamental para um trabalho que se diz transformador, aberto, crítico. Muitas vezes é preciso que um professor avalie o outro mutuamente para acordarem e se conscientizarem da alienação que envolve suas ações.

A professora Nate foi muito sincera quando afirmou que, ainda que troquem muitas ideias, existem muitos aspectos que precisam ser ressignificados, e sempre existirão, pois nada é para sempre; o que está bom hoje, amanhã poderá estar ultrapassado. Daí a necessidade de um processo reflexivo, contínuo, sistemático do professor acerca de sua prática docente.

0 que essa fala mostra, também, é que o cotidiano da professora é repleto de surpresas. Muitas vezes ela percebe a necessidade de improvisar, tomar decisões momentâneas que sejam eficientes, pois a prática nunca é a mera concretização do que se planeja. 0 dia a dia da professora é constituído, muitas vezes, de pequenas decisões rápidas e impensadas. 0 que a professora faz ou deixa de fazer nestes momentos precisa ser refletido. Se a atividade for simplesmente para ocupar o tempo e não ter sentido algum para ser realizada, é melhor que nem seja feita, conforme afirma Nate, porém é preciso que o professor seja criativo e rápido para criar atividades momentâneas significativas, pois o tempo que ele passa com os alunos é precioso.

Em dezembro foi analisada a última aula da Professora Nate. A escola toda estava em período de recuperação e a professora havia dispensado, como todos os demais professores, os alunos que conseguiram atingir os objetivos propostos para aquele ano. Oito alunos haviam ficado em recuperação e era com estes alunos que ela estava trabalhando no dia da filmagem. Estes oito alunos já estavam alfabetizados, e com a mediação da professora, realizavam 
atividades que desenvolviam a habilidade de ler e escrever.

Rita: Porque eu achei super consciente da parte de vocês quando outro dia a Nate me disse que a Direção havia pedido para vocês enviarem por escrito a relação dos alunos fortes, médios e fracos para eles definirem as turmas para o próximo ano, e vocês não o fizeram. No entanto, esta semana de recuperação vocês dispensaram os chamados 'fortes' e ficaram com os 'fracos'.

Ceci: Eu, pessoalmente, acho que isso empobrece.

Rita: Nós não fazíamos mais recuperação desta forma.

Nate: Ano passado nós recomeçamos a fazer. Sabem o que me deixou abismada com o que vocês colocaram? Se todos nós somos contra... eu na verdade nem pensei se era contra na hora, mas por que nós estamos agindo assim? Por que nós não discutimos isso antes? Isso que eu fiquei me martelando. E tu como orientadora, Ceci? Para mim e para a Ange, uma palavra só bastava.

As discussões que surgiram na análise acima revelam o quanto as professoras realizam atividades impensadas, cristalizadas, que se chocam com as suas verdadeiras concepções. Para mudar aspectos tão rotineiros na escola é preciso uma consciência coletiva. Uma professora só, muitas vezes, não se sente capaz de mudar algo tão enraizado no sistema escolar. Muitos professores ficam esperando que a Direção tome, por conta própria, uma decisão de mudança, o que muitas vezes não acontece. É preciso que se construa um coletivo escolar que busque avançar sempre.

Esta pesquisa buscou desenvolver um trabalho coletivo. A cada encontro a relação entre o grupo aumentava, o pensamento do outro se desvelava, tanto que, muitas vezes, as falas se completavam, o dizer de um passava a ser do outro, construindo-se, assim, concepções partilhadas. Portanto, a análise coletiva fortalece tomada de decisões, as discussões tornam-se mais ricas e profundas e os caminhos a seguir são mais seguros. 0 processo dialético de ser formador e formado simultaneamente permite ao sujeito uma dupla forma de se desenvolver, de perceber a realidade. Entretanto, "a inovação só tem sentido se passar por dentro de cada um, se for objeto de um processo de reflexão e de apropriação da pessoa" (NÓVOA, 1998, p. 30). Não basta simplesmente participar de um coletivo. É preciso que o indivíduo se envolva e queira mudar. É o professor o sujeito de seu processo de mudança.

\section{Considerações Finais}

O enxergar-se no vídeo muitas vezes bastava para a professora se autoavaliar e perceber aspectos plausíveis de serem superados. Entretanto, as colegas ajudaram a perceber aspectos que eram ignorados pela professora, até mesmo após refletir sobre sua própria prática em vídeo. Assim, a análise coletiva e compartilhada possibilitou uma reflexão diferenciada da prática de cada professora, surgindo questões novas irrefletidas pelas próprias professoras. 0 movimento compartilhado de negar, confrontar, rearticular ideias gerou novos conhecimentos e novas atitudes por parte das professoras. Estabeleceu-se uma intimidade/coletividade muito forte entre os componentes do grupo. Compreendemos que isso foi um aspecto importantíssimo para que as críticas e as sugestões pudessem ter sido refletidas, internalizadas e ressignificadas pelas professoras. Esta intimidade/coletividade chegou ao ponto de fazer com que as próprias professoras se visitassem no dia a dia, em sala de aula, e se criticassem mutuamente, sempre que surgisse algo questionador, alastrando suas reflexões, independente do Grupo Reflexão-Ação.

Cada professora passou a refletir mais sobre sua própria prática, sobre a prática da colega, sobre o que fazem, o que deixam de fazer. 0 Grupo Reflexão-Ação contribuiu com o movimento de ação-reflexão-ação das professoras participantes, principalmente no que se refere ao planejamento, ao trabalho de grupo em sala de aula, e no próprio entendimento dos aportes teóricos discutidos. 
Na perspectiva histórico-cultural, o debate entre professores é fundamental, pois ela entende que é no confronto de ideias opostas que os interlocutores assumem o papel de mediadores. No grupo, cada professora pode elaborar análises que não elaboraria sozinha, confirmando a concepção de Zona de Desenvolvimento Proximal de Vigotski. Houve avanços no grupo sempre que ocorriam análises e reflexões críticas a partir da contribuição de parceiros mais experientes.

Para que os professores ressignifiquem a sua prática é preciso que a teorizem. E este movimento de teorizar a prática não se efetiva somente com treinamentos, palestras, seminários, aulas expositivas, mas muito mais quando há uma relação dinâmica com a prática deste professor, a partir de uma reflexão coletiva, autorreflexão, pensamento crítico e criativo, e educação continuada. É preciso desencadear estratégias de formação processuais, coletivas, dinâmicas e contínuas. Refletir com os demais professores e compartilhar erros e acertos, negociar significados; confrontar pontos de vista surge como algo estimulador para uma prática docente comprometida.

Esse espaço complexo, cheio de recuos e avanços, transformou-se em cumplicidade mútua, em que a mudança de uma professora gerava a mudança de outra e, consequentemente, a do grupo todo. A mudança não surge por acaso, ou somente a partir de pacotes ou receitas impostas ao professor, mas muito mais por práticas coletivas, que reflitam a ação. Muitas vezes, quando o coletivo se volta para uma análise crítica do fazer do outro, muitas questões são doloridas e angustiam. Abrir espaços para a reflexão/construção da sua própria prática exige uma consciência crítica. Conviver com os contrários, respeitando diferentes opiniões e permitindo a intervenção do outro como elemento mediador da própria prática, é um crescimento tanto para o professor analisado quanto para o analisador. 0 assumir estes diferentes papéis engrandece.
Toda pesquisa coletiva requer interação, confiança, respeito, credibilidade. Analisar coletivamente a prática docente como realmente ela acontece foi possível graças à consciência do grupo de professoras, por ser aberto às críticas e ter um forte desejo de crescer profissionalmente. Professoras que buscam aperfeiçoar-se constantemente e que acreditam que é nas trocas com outros profissionais, compartilhando dúvidas e possíveis certezas, que se amplia o conhecimento. Professoras conscientes de que correr riscos é necessário quando se busca alguma transformação. Professoras corajosas que não tiveram medo de mostrar seus erros, mas que passaram a perceber que expor o erro pode levar a novos acertos.

Ao aprofundarmos um estudo sobre a prática pedagógica e concebendo-a como um processo que está em constante construção, fazendo-se e refazendo-se, fica difícil apresentarmos um modelo de professor ideal, ou pregar que uma única perspectiva (histórico-cultural) é a melhor. Novos paradigmas educacionais surgem com o passar dos tempos, renovam-se, negam-se, entrelaçam-se. É preciso uma busca constante. Concluímos que as ideias de Vigotski não podem ser compreendidas como uma resposta completa, única, acabada, pois não há certezas definitivas quando se trata de algo tão complexo como o ser humano. Também não podemos esperar que os aportes teóricos de Vigotski apontem respostas às inúmeras interrogações acerca do processo de desenvolvimento e aprendizagem. No entanto, no momento, compreendemos que a prática pedagógica alicerçada nas ideias de Vigotski representa uma tentativa possível, consistente e comprometida na busca de um caminho que leve a um melhor processo pedagógico.

Ao final, ao contextualizarmos a importância desta pesquisa para a comunidade educacional, ressaltamos todo um conhecimento historicamente construído por um grupo de professoras que buscaram alternativas de manter uma relação mais íntima entre sua ação/reflexão 
e encontraram, em um estudo compartilhado -reflexivo, um caminho para isto. A socialização desta caminhada poderá ser útil em situações de formação de professores, incentivo à formação centrada na escola e à constituição de comunidades de prática na escola.

\section{REFERÊNCIAS}

ANDRÉ, M. Eu, professora-avaliadora. Cadernos de Pesquisa, São Paulo, n. 105, p. 78-91, nov. 1998. NÓVOA, A. Os professores e sua formação. Lisboa: Dom quixote, 1997.

NÓVOA, A. Relação escola-sociedade: novas respostas para um velho problema. In: SERBINO, R. et al. (org). Formação de professores. São Paulo: Edunesp, 1998. p. 16-39.

SÁNCHEZ-VÁZQUEZ, A. Filosofia da práxis. São Paulo: Expressão Popular, 2011.

THIOLLENT, M. Metodologia da pesquisa-ação. São Paulo: Cortez, 1985.

VIGOTSKI L. S. A formação social da mente. São Paulo: Martins Fontes, 1987.

VIGOTSKI. L. S. Psicologia pedagógica. 3. ed. São Paulo: Martins Fontes, 2010.

Recebido em: 01/01/2020

Aprovado em: 25/02/2020

(cc) BY-No 